\title{
THE ANNALS
}

AND

\section{MAGAZINE OF NATURAL HISTORY.}

\author{
[THIRD SERIES.]
}

No. 80. AUGUST 1864.

IX.-Observations on the various Species of Glyptodon in the Public Museum of Buenos Ayres. By Hermann Burmeister, M.D., Ph.D. \&c.*

TнE soil of the province of Buenos Ayres is one of the richest deposits of fossil bones on the surface of the globe. Considering that the existing specimens, of intrinsic and of scientific value, had almost all been transferred to European museums, and that it would be an easy task to found a more precious collection in Buenos Ayres, if the national administration should interest itself in the preservation of the natural treasures, I accepted the invitation which, through the medium of the Prussian Minister, Herr von Gulich, the Supreme Government sent to me during the time of the administration of Señor Sarmiento. As Director of the Public Museum, I resolved to devote myself exclusively in future to the study of the natural productions of Buenos Ayres and of the other Argentine provinces. During the two years that I have been occupied in this new employment, the Museum of Buenos Ayres has completely changed its contents: I have arranged them in the European manner, as the collections exist in that part of the world; and I have, up to this time, introduced so many new specimens of fossil bones, that, withont exaggeration, it may be said that no European museum is more rich in these than that of Buenos Ayres. To prove the correctness of this statement, I shall publish, from time to time, notices and scientifie descriptions of the principal specimens, commencing with our skeleton of Glyptodon, which,

- Translated from the 'Revista Farmacéutica de la Sociedad de Farmacia nacional arjentina, ${ }^{2}$ 1863-64, by C. Carter Blake, F.G.S., F.A.S.L. [The translator has had the advantage of a copy in which Dr. Burmeister has introduced many manuscript corrections into the original Spanish printed text, and of illustrative photographs and pencil drawings of the specimens.]

Ann. \& Mag. N. Hist. Ser. 3. Vol. xiv. 
up to the present time is unique in the museums of the civilized world. Señor Don David Lanato having presented this precious specimen to the Public Museum, I set it up myself, during the first months of my direction (1860), with the assistance of some friends and skilled workmen, who helped me in the steel- and iron-work, I myself superintending their manual labour. To clearly explain the parts of this antediluvian animal which are new to science, and those which are already known, I must give some historical notices of previous publications on the same subject.

The first notice of this animal will be met with in the work of the celebrated Cuvier*, in which that author states, in a note, that Señor Damaso Larrañaga, of Montevideo, discovered in Banda Oriental the shell of a gigantic animal, which probably belonged to Megatherium. The Prussian traveller Sellow was the first who (in the year 1825) sent specimens of this shell to Europe, where they were described by the celebrated mineralogist Weiss, in the Transactions of the Berlin Academy for 1827, without a knowledge of the zoological affinities of the animal to which they belonged, the author being, however, disposed to regard them as the armour of Megatherium - an opinion which, some years after, was directly accepted and published by the English author Clift $\uparrow$. Buckland, in his 'Geology' $†$, expressed the same opinion. With the specimens of the shell which were then obtained, some parts of the skeleton were also sent to Berlin, and, with those which were examined by my friend and colleague in the University of Halle, Dr. D'Alton, this celebrated anatomist published, in the Transactions of the Berlin Academy for 1833, the description of the incomplete forearm and some foot-bones of this animal, he calculating that it bore an affinity to the Armadillo, but that, until the entire form was discovered, it would be futile to assign to it a specific name. The celebrated English anatomist Owen coincided in this judgment, five years after, when he described the shell and some portions of the skeleton which had been recently sent to London by Charles Darwin and by the English Minister in Buenos Ayres, Sir Woodbine Parish $\S$, and gave to it the new name of Glyptodon clavipes, derived from the carved [or fluted] form of the teeth and the thick form of the feet. To the description of these parts the author has made several additions in his work on the fossil bones in the collection of the College of Surgeons of Lon-

* Recherches sur les Ossemens Fossiles, \&c., vol. v. part 1. p. 191, ed.
1823.

Notice on the Megatherium, Trans. Geol. Soc. 1835.

\# Bridgewater Treatise. 8vo, London, 1837.

Trans. Geol. Soc. vol, vi. p. 81 ; Zoology of the Beagle, vol. i. 
don*, and also introduces three new species, which he terms Glyptodon ornatus, G. tuberculatus, and G. reticulatus, founding the specific differences on the varied form of the plates of the surface of the shell. But as the foot of the animal described in the last publication of Owen was incomplete, Müller, the celebrated physiologist of Berlin, published a fresh description of the entire foot in the Transactions of the Academy of Berlin for 1846.

All these descriptions were founded on specimens discovered in the province of Buenos Ayres or in the Banda Oriental. There are undoubtedly remains of the same animal in other parts of South Ameriea, but in no other part of the world. In Brazil, a Danish naturalist, the learned Dr. Lund, occupied himself for a long time in the study of the fossil bones discovered in the natural caverns of Minas Geraes. Amongst these, remains of the Glyptodon were discovered by him; but as he was not aware of the works recently published in Europe, he deseribed the animal under a new name, terming it Hoplophorus, from the "strong shell," and signalized three species, Hoplophorus Sellowii, $H$. euphractus, and $H$. minort. A year afterwards; he published in the same 'Transactions' (vol. ix. 1842) the description of new fragments, and amongst others the teeth, and the five sacral vertebræ in one piece.

Such was the state of the scientific knowledge of Glyptodon before the publication of the work of M. Nodot, Director of the Public Museum of Dijon in France, to whom a French resident had transmitted from Buenos Ayres many portions of the Glyptodon and an almost complete shell. This work has not yet fallen into my hands, and for this reason $I$ am ignorant of its contents excepting from the notices in scientific journals, which state that its author recognizes fourteen species of Glyptodon, dividing them into two divisions, Glyptodon and Schistopleurum, founded respectively on the Glyptodon clavipes and the Glyptodon tuberculatus of Owen. To the Glyptodon belong twelve species; which are again subdivided into two groups by the form of the tail, which in some is short and conical, and in others is long and cylindrical.

Finally Prof. Huxley, of the College of Surgeons of London; has published some notices on an incomplete skeleton presented to the Museum of the Royal College of Surgeons by Señor Don Juan Nepomuceno Terrero, of Buenos Ayres; and the brother of this gentleman, Don Federico Terrero, has published a trans: lation of Huxley's description in the 'Nacion Argentina' of the lst of July of the current year, to which he has added some

* Descriptive Catalogue of the Collection of the Royal College of Surgeons, vol. i. London, 1845.

† Trans. Royal Academy of Copenhagen, vol. viii. 1841. 
supplements in the same periodical of the 25th of July, referring to the general description of the specimen in our museum, published by me in the 'Nacional' of last year, No. 3140.

Entering now upon the description of the specimens in the Public Museum of Buenos Ayres, it appears to me necessary to keep in mind that the number of species in our formations are not more than three, which are distinguished by the structure of the plates on the surface of the shell, and even by the general form of the shell itself. These plates form regular hexagons in the centre of the buckler, changing at the sides into prolonged hexagons, and very often into pentagons at the edges. In the same manner the hexagonal figures are arranged on the surface of each plate. There are seven on each plate, one (the largest) in the centre, and six on the six sides, which are in contact with the contiguous plates to form other hexagons on the joints between them. These figures are separated by grooves, and in these are discerned, in the corners of a median hexagon, small apertures to receive the roots of the long hairs which pass through the shell of the living Armadillo. The surface of each hexagon is rough like a file; and upon this asperity a smooth horny shield existed, as in the existing Armadillos. But the size of these hexagons of each plate varies in the different parts of the shell, those in the centre being relatively more equal, and the peripheral portions more unequal, in such manner that the central hexagon of the plates occupies more space towards the centre of the shell, whilst these proportions diminish towards the edges. It results that the last plates at the edge of the shell form large, nearly circular hexagons, and in the circumference alone are some very small figures which form the half of the peripheral hexagons. In this way the collocation of the loose plates in the whole shell can be ascertained; but in no way are we able to constitute specific differences on the form of the entire plates or the figures on their surfaces.

The same difference between the size of the central figure and the peripheral ones of each plate may also be recognized in some existing Armadillos, as in the Mulita, which possesses the same structure of the shell-a fact which is demonstrable on the smooth horny scutes which cover the hexagonal pattern of the plates.

These existing animals are to be met with in South America alone, like the antediluvian Glyptodon of other times, and are divisible into two principal classes. One, which naturalists term Dasypus, comprises such species as the Peludo (D. setosus), the Mataco (D. conurus), and the Pichy (D. minutus), with plates almost equal in all the parts of the shell, and covered with smooth horny scutes of the same pattern and size. If some, 
like the Peludo, have large hairs on their shells, these hairs issue from the junction of the plates. The others, which are termed Praopus, such as the Mulita (P. hybridus), have plates more or less unequal, covered with two elasses of horny scutes, one large one in the centre on each side, and six smaller at the junction of the plates. In these, the hairs which issue from the shell do not proceed from the joints, but from the same plate in the circumference of the central scute.

The description of the shell of Glyptudon demonstrates that this antediluvian animal was constructed on the same principle, but that it resembled Praopus more than Dasypus; nevertheless there is a difference between Glyptodon and Praopus, in consequence of the absence of the moveable rings in the middle of the shell, which the living Armadillos possess in varied number in the different species.

There is an important difference in the surface of the shell between Glyptodon tuberculatus and other species, G. tuberculatus not possessing the large hexagonal figures in the plates common to the other species. In G. tuberculatus the surface of each plate is covered equally with small irregular figures, upon which, without doubt, were placed concomitant horny plates, so that the superficies of the shell exhibits the same appearance. Some small holes amongst the small figures demonstrate also the existence of hairs in the shell, but they are more sparse, although each plate also, in its original formation, appears to have possessed six small apertures on its surface. On the edge of the shell are seen large hemispherical or conical tubercles, externally very rough, and covered with a smooth horny shield of the same form. The size of these tubercles varies according to their position in different parts of the edge, increasing in size towards the posterior part. On the shoulders chiefly these tubercles are more conical and sharp than those on the head and sides, where it appears to me there are some smaller and more conical moveable tubercles, below the edge of the shell and upon the legs. I have many of these tubercles in the Museum, but I am ignorant of their collocation on the body of the animal ; nevertheless M. Nodot states that his Schistopleurum had moveable rings at the side of the shell, which he has not recognized in any Glyptodon of the Museum, unless in the above-mentioned smaller tubercles. These, by the form of their basal parts, demonstrate that they are placed on the same cutis, and are united to other parts of the shell.

As a general character of the whole shell, it may be observed that the central plates become in time united in an entire piece, whilst those of the side are separated and united one to the other by joints. This separation of the plates continues until 
the adult state of the animal, and for this reason the shells are generally fractured or broken on the edges. Complete shells, with all the parts and tubercles on the edges, are very scarce, and rarer in proportion to the youth of the animal.

As regards the specific differences between the Glyptodons of this country, I cannot distinguish amongst our rich collection of Buenos Ayres more than three-G. clavipes, Owen, G. tuberculatus, Owen, and a species which I provisionally name G. spinicaudus, for want of the original works which describe other species.

The most abundant amongst these three species is the last, of which we have in the Museum an almost entire shell, a complete skeleton, and more or less important remains of three individuals. The species is distinguished easily by its short and conical tail, having seven rings of large conical tubercles; and for this reason I have given it the name of G. spinicaudus. Probably the G. ornatus is identical with this species. As the shape of the tail is the most important feature, we shall begin with its description.

It is 22 inches in length, 14 in width at the base, and 4 at the apex, which is obtuse and round. At the base are seen six rings of conical tubercles, which are more or less narrow. Each ring is composed of three bands of plates, the last one being formed of the great tubercles, whilst the two preceding ones are smooth, and almost wholly covered by the anterior rings. The first ring is the largest, and of a transversely elliptical shape, having twenty-three tubercles on the posterior edge, the nine lower ones being smooth, and the upper ones more elevated into a conical point according as they approach the middle of the dorsal surface. The second ring is of an almost circular figure, and with eighteen tubercles on the edge, the inferior surface being smooth in almost all the lower rings. In the same manner, the third ring has fifteen, the fourth eleven, the fifth nine, the sixth seven tubercles; and the extreme portion is formed by a ring of five, including amongst them three at the apex itself. Of all these tubercles, those of the middle of the dorsal surface are always the largest, and prolonged into a conical point. The shell of this species is in its general form more spherical than that of some of the others. Its length, following the curve, is about $3 \frac{1}{2}$ yards (varas), and its width about $2 \frac{1}{2}$; only the posterior part near the tail is a little uncovered; the longitudinal diameter is $5 \frac{1}{3}$ feet, and the transverse diameter is about $3 \frac{1}{4}$. The surface of the plates is very rough, much more so than in the other species, and the size of each plate smaller. The central hexagon of the dorsal plates of the shell is smaller than in G. clavipes, and for this reason the difference between the central 
figure and those of the periphery is little or nothing: all the hexagons of this central part of the shell are of equal sizo.

Also the tubercles of the edge of the shell are smaller and different in shape; these tubercles have, in G. clavipes, a low conical elevation on the external surface, which is wanting in G. spinicaudus. In this species are seen about sixteen tubereles at the posterior edge of the shell over the tail, and about twelve on the anterior edge over the head. The lateral tubercles are almost wholly wanting, and for this reason I do not know its exact shape; only, upon the shoulders, these large conical tubercles may be seen to be a little curved above, and are of the same sort as those of which we have before spoken.

The head bore also on its superior part a shell of plates much smaller and irregular, but of the same construction as those of the shell. It is not in my power to describe it in detail, in consequence of that which we have in the Museum being broken. The same applies to the feet-without doubt well armed with plates like those of the living Armadillo, and having at the end of the toes large claws, of which there are four long ones on the anterior and five wide ones on the posterior extremities. There are a great quantity of small plates, very diverse in form and size, preserved in the Museum, which show by their construction that they were derived from the same skin. These plates probably belong to the feet and to some of the small joints, where the existing Armadillos have equally small plates, of partly formed shell.

The second species from the Buenos Ayres soil is G. clavipes, of which there exist in the Museum an imperfect shell and two tails. Undoubtedly it is larger than the first, although, as it is broken, we are not exactly aware of its dimensions; but the larger size of this animal is not alone demonstrated by the greater size of the loose plates of the shell, but by that of the bones of the skeleton which we have in the Museum. At the same time, it appears to me much more narrow and elongated than G. spinicaudus. The specific difference is very clear in the side plates of the shell,-the central hexagon being larger than the peripheral hexagons, and the structure of the surface being finer, less elevated, and less rough. The tubercles of the edge of the shell appear less convex, and the centre of the external superficies is a little elevated, as we have said above, compared with the tubercles of $G$, spinicaudus.

But the most distinguishable character of this species is the existence of a peculiar semicircular border below the tubercles of the edge, covered with rhomboid figures. This border does not exist in Glyptodon spinicaudus. The tail is very different, being long, thin, almost cylindrical, with some rings at its base 
and a curved tube at its posterior portion. How many rings there were I do not know, as all the tails met with up to this time are broken; but it is very probable that the number of the rings of the tail were equal in all the species, that is to say, six. Each ring bears two or three bands of plates much finer than those of the shell, and of oblong form, each one presenting an elliptical scute in the centre and angular ones in the periphery. The figures here are almost smooth, and are deficient in the superficial rough structure of the shell. The posterior part of the tail forms an almost cylindrical tube a little curved, and thicker at the base than at the obtuse point. The surface of this tube has the same elliptical figures as the rings at the base, and between them a band of other, angular and much smaller figures. At the sides of this tube the ellipses change more or less into circles, and on the side itself is formed another band of much larger ellipses, which augment in size gradually to the point of the tail, the two immediately at the end being the largest.

The third species from Buenos Ayres is G. tuberculatus, which M. Nodot has erected into a separate genus-Schistopleurum*. The different form of the plates on the surface of the shell above described easily distinguishes this group from the others. It is the largest of the three, and is double the size of $G$. spinicaudus. We only possess in the public Museum some pieces of the shell, and the posterior portion of the tail, of the general form of which we are consequently ignorant. M. Nodot states that at the edge of the shell there are some bands of moveable plates, and that for this reason he has separated this species from the others to form a particular group. There are in the Museum some plates of oblong form, with a large elliptical figure on the surface, and other smaller and irregular ones on the periphery. These plates form a kind of large ring, which is probably one of the moveable parts of the side of the shell. But it appears to me that it belongs to the posterior edge of the shell from which issues the tail, forming between the posterior cylindrical part of the tail and the shell some moveable rings, as in the other species. How many rings there were I do not know; but it is permissible to believe that there were six. The posterior portion of the tail of the animal which we have in the Museum is complete, and is 1 yard in length and 5 inches in breadth; its superficies is covered with the same small irregular figures as the shell; but between them we can see large ellipses as in the rings described. These ellipses are very different in pattern

* [Now well known in England by Mr. Gregory's excellent restoration. -TRANSL.] 
and size, forming in the beginning of the tube two circles of eight small ellipses in each, and at the side three other bands of other and larger ellipses; the ellipses of the median band are much larger and more extended towards the point of the tail, where are to be seen two of a longitudinal diameter of 8 inches. But a large part of the tail of the same species in the Museum, recently discovered by me on the banks of the river Salado, is twice as long, which demonstrates that this animal was capable of attaining a truly gigantic size. The distinction between the three species is easy, as the foregoing description proves; but it is not easy to know whether the other species already described are well founded. Mr. Owen has further accepted two species, which he terms $G$. ornatus and $G$. reticulatus. Of the first he says that it is smaller than $G$. clavipes-a character which appears to indicate its identity with $G$. spinicaudus; but, without a knowledge of the shape of the tail of G. ornatus, it is not possible to know whether the two are really identical or different. Of $G$. reticulatus the author says that it is of the same size as $G$. clavipes, but different in its structure, which is reticulate on the surface of the shell-plates-a character which might apply to the plates of G. tuberculatus which are situated in the centre of the shell.

The three species of Hoplophorus, founded by Dr. Lund, I only know by the description of some parts which the author has given in the work already cited. They show a great similarity to the Glyptodons of Buenos Ayres ; but, without an exact comparison of the objects themselves, it is impossible to know whether they are identical or different.

The accounts which $\mathrm{I}$ have read of the work of M. Nodot state that the author has established fourteen species, without specifying their differences; and for this reason we cannot arrive at any judgment whether they are well founded or not. It appears that we have accepted all the species already enumerated by different authors; but in this case the number of fourteen appears to be exaggerated, as can be proved by an examination of the three different species from Buenos Ayres.

Let us now pass to the examination of the skeleton.

For some time the feet, the tail, and the head of Glyptodon have been incompletely known. The same statement applies to the vertebral column and to the pelvis, recently described by $\mathrm{Mr}$. Huxley, as the skeleton which was in his hands was very defective, which has consequently rendered his description very incomplete.

In the Museum of Buenos Ayres there is a nearly complete skeleton, known up to the present time by a photographic figure made by the able artist Señor Aldanondo (Calle Florida, 129), 
and the more or less important remains of five more individuals, amongst which we have met with some specific differences from the two principal species from the soil of Buenos Ayres. Let us first describe the skeleton in general.

The skull is very thick, and, comparing it with the acute skulls of existing Armadillos, is very short and obtuse. The nasal bone, the forehead, and the vertex being in the same plane with the occiput, form a flat surface of 11 inches in length by $5 \frac{1}{2}$ in width between the eyes. This short figure depends principally on the shape of the nasal bone, which is so short that the point of the lower mandible by far surpasses that of the upper, which latter was in this animal much longer-in the living state, as there then existed a broad and strong cartilage in this organ somewhat prominent from the head. It is probable that the living animal might have had a thick and strong snout, to grub up the earth, and seek its food in this manner, as the Armadillos do at present. It is not very evident up to what point the cranial bones extended, from the want of sutures of the skull, since it is entirely in one piece, and destitute of any suture, without any vestige of the primitive bones of the young animal. Neither can the frontal bones be distinguished from those of the vertex nor from those of the occiput, because they are all united-in one capsule. The perpendicular part of the occiput is very low, and the foramen occipitale is of a transversely elliptical shape, which is not met with in any other mammal. The internal cavity of the cranium is of a surprising smallness, as was also the brain; and these characters indicate that this was an animal exceedingly stupid and sluggish-qualities which are also indicated by the size of the lower mandible and the great extent of its grinding-portion.

There is no other animal which has so descending a palate (sic in orig.) nor such projecting teeth as the Glyptodon. Above all, the ascending ramus of the inferior mandible is very high, in such a proportion that no animal equals it in this respect. The anterior inclination of this ramus, which forms with the horizontal ramus an angle smaller than a rectangle, is a character peculiar to the Glyptodon; and this inclination indicates a powerful grinding-apparatus, which surpasses that of other Mammalia, even that of the Elephant. The symphysis is produced, like the spout of a jug (la boca de un cántaro), this part being toothless; there are eight teeth on each side of the inferior and superior mandibles, more or less alike in form; but those of the upper mandible are a little larger, and those of the fore part of each jaw slightly narrower.

Each tooth is formed by the conjunction of three rhombic prisms, which have on each side deep excavations between the prominent points of the three prisms. This form may be com- 
pared with that of the teeth of the Carpincho: it is peculiar to the Glyptodon, because no other animal equally large possesses teeth of this form. The zygomatic arch of this animal, besides being thick, was provided with a perpendicular prolongation which descended from underneath the eye, giving us a proof that it ground hard substances. This prolongation is only discovered in antediluvian animals, such as the Megatherium, Mylodon, or the Scelidotherium*.

As we only intend to describe the principal parts, I shall here conclude the cranium, and shall give a description of the differences in the teeth of the various species of the animal, they being the only parts which ean be compared one with another.

I have in my possession portions of three lower mandibles, two of which belong to G.clavipes, and the other (which is complete) to G. spinicaudus. The general form and the relations of the teeth are the same; but the form of the prisms in each tooth is a very little different. The sides of each rhombic prism of G. clavipes are a little curved into the interior of the prism; but those of G, spinicaudus have a slight external elevation ; and for this reason the dental prisms in the former species appear to be thinner and more acute at the corners, and those of the second thicker and more obtuse. In the work of Dr. Lund (second part, tab. 35. f. 2, $3 \& 4$ ) there are figures of two teeth which appear to exhibit a slight difference, as regards the form of the prisms, from those of my two species, demonstrating that there was a slight difference between the Brazilian species and those of Buenos Ayres. These teeth are from the upper jaw,-fig. 2 being the first, and fig. 3 the last tooth on the left side.

The neck of the Glyptodon comprises seven vertebræ, as in other Mammalia ; but only the first and the last are moveable, the other five being united into one solid mass; hence it results that the neck is very short and powerful. The first, or atlas, is of considerable size, and of the form occurring in other Mammalia; its two wings are laterally compressed, ascend posteriorly, and have three smooth and even slightly concave excavations for their articulation with the second vertebra. This (the axis) is short and united with the four following ones in one piece, which developes in front a small tuberosity for its articulation with the atlas. At each side of this bone there is a strong prolongation inclined backwards, and before it four foramina for the transmission of nerves, which indicate the five united vertebræ. There is another prolongation on the top of the arch above the vertebral column, which is also inclined backwards, and is terminated by three points. This particular bone is already known

* [It is also visible in the existing Sloth.-TransL.] 
by a description and a drawing in the second part of the work of Dr. Lund (tab. 35. fig. 1).

The seventh vertebra is moveable and free, but maintains almost the same form as one of the four which are united with the axis. It is a very small bone, transversely elongated, with a large, almost triquetral perforation in the centre, and three processes-the upper one short, and the other two strong ones at the sides. The lower portion, which in other Mammalia constitutes the rather thick body of the vertebra, is a very delicate plane, of scarcely any thickness in the centre, and half an inch in breadth.

The vertebral column, or spine, appears to me to be the most remarkable part of the animal, it being a solid arched canal, without division into separate vertebræ in conformity with the rule in other mammals. This vertebral canal is bent, as the form of the animal requires, and is armed in its superior part with three crests, of which the middle corresponds to the spinous process [neural spine, Owen], and those of the sides to the transverse processes [or rather to the metapophyses, Owen] of each vertebra in other Mammalia. But of the body [centrum] of the vertebra, which in Mammalia is generally very thick, nothing is seen; and the lower part of the canal, which corresponds to the bodies of the vertebræ, is most fine and thin in all its circumference. The canal alters in shape a little: towards the fore part it is wide and low; and towards the back, little by little, narrower, but higher, and in this way the three crests meet. The whole of the vertebral canal is divided into three parts, of which the two anterior correspond to the dorsal vertebræ, and the third to the lumbar vertebræ.

The first part of the canal is the smallest; beneath, in the lower part, it is about $2 \frac{1}{2}$ inches long, and 4 inches above. Its width in the middle is about 7 inches. It is composed of three united vertebræ-the first small, nearly of the same size as the last cervical vertebra, and the other two larger, demonstrated by the holes in the sides, from which issue the nerves of the myelon. The upper surface is smooth, and exhibits a high and thick backward prolongation, which rises considerably at the sides of the bone. Here we see two other prolongations, which correspond to the transverse processes of the three vertebræ: the first is very strong, prolonged in an anteroposterior direction backwards, and corresponds to the first two vertebræ; the second is very short and thin, but also broad. On these processes we see the articulations of the first three ribs - the first in the anterior part of the first prolongation, the second in the posterior part, and the third in the exterior part of the second prolongation. This first, trivertebral part is 
joined with the following bone of the vertebral canal by means of a very moveable articulation, so as to raise itself and retract itself on the neck. In the same manner the head moves itself by the operation of this trivertebral bone enabling it to enter more or less into the interior cavity of the shell, and to protect itself in this retired position from the attacks of other animals, in the same manner as the existing Armadillo. If it were not for the presence of this bone, the head of the animal could not move itself out of the shell, or, at will, retract itself within.

Mr. Huxley, who very well describes this bone as a piece composed of three vertebræ, supposes that the great mobility of this bone was necessary for the respiratory motion of the thorax, the ribs not being sufficiently moveable at their articulation with the vertebral tube. I cannot participate in this opinion; on the contrary, the true function of this trivertebral bone is to facilitate the motion of the head both forwards and backwards, as I have already explained. There is no difficulty in the motion of the ribs on their articulations, notwithstanding that there is a remarkable difference between their conformation and that of other Mammalia, as is proved by the form of the articular excavations at the side of the vertebral canal.

The second part of the spinal canal is the longest; it is 17 inches in length in its curvature, and about $3 \frac{1}{2}$ inches in breadth forwards, gradually diminishing to 2 inches. The anterior part is smooth, with the first and inferior of the three crests ascending gradually higher on the upper side, having ten round foramina on each side of the canal, for the transmission of the nerves of the myelon, which proves that this part of the canal was composed of eleven united vertebræ; but there is no vestige of external separation on the surface. Besides, we see on each side, outside the lateral crests, eleven articular impressions of a peculiar form, like a $\mathcal{O}$, for the ribs which unite by them with the spinal canal.

The third part of the spinal canal unites with the end of the second part, not by an articulation, but by a cartilaginous and moveable juncture, which anatomists term synchondrosis. It is - by this that the edges of the canals which are in contact slightly extend towards the sides. The part of the vertebral column which follows is also different in form, being a little broader, and, on the dorsal surface only, armed with a very high median crest, but without transverse processes on either side, in consequence of the absence of the ribs.

But there is in the beginning of the canal, and on each side of this high dorsal crest, a process which projects forwards, and is in contact with the end of each lateral crest of the second part. In this process there is also the half of the articular excavation 
which receives the ribs. But below the lumbar canal, there are on each side some rather large foramina for the nerves which issue from this part of the myelon. I have counted in the two lumbar canals which are in the Museum, belonging to Glyptodon clavipes, six of these foramina, and in the same canal of the $G$. spinicaudus seven, which proves that the number of vertebræ united in this canal are six in the first species and seven in the second. There are probably corresponding differences in the anterior part of the vertebral canal of the two species, that of the $G$. clavipes : being much larger and consequently more numerous in the vertebræ. The last part of the lumbar canal immediately unites with the sacrum without any articulation; the two appear to be the same bone.

The os sacrum is formed of nine vertebræ united in one solid mass, which is broad and thick at the commencement, thin, long, and high in the centre, and thick with two long prolongations, one on each side, at the end. The first part is composed of three rather short vertebræ, which unite forward with the pelvis, and constitute with it a very high crest, on which the shell of the animal is supported. The second part is composed of five rather long vertebræ, and is in the figure of a curved tube, with a high crest on its upper part. Five foramina on each side of the tube, for the nerves of the myelon, indicate the number of vertebræ in this part of the sacral bone. At the end, it extends at its base into a solid and thick mass, which assumes the form of the body of a vertebra, and is actually the last vertebra of the sacral bone. On each side of it a horizontal prolongation extends, smooth and broad, which corresponds to the transverse process of the vertebra, and by this prolongation the os sacrum unites for the second time with the pelvis. Another small prolongation of the penultimate vertebra also unites with this horizontal branch. The sacral bone of the Armadillos is formed in the same manner, especially that of the Mataco.

The pelvis is the largest part of the skeleton, and is of a very peculiar form. Its thickness is caused by the fact that the whole weight of the shell of the animal is superimposed on it, as it is the only bone which unites immediately with the shell. For this reason the pelvis extends forward and backward into two great perpendicular alæ which gradually augment into very broad and strong crests, armed with many obtuse tuberosities, which impinge upon other similar ones on the inferior surface of the shell, having between them large cushions of an elastic cartilaginous substance, to sustain the weight of the shell more easily, and to permit its more facile elevation during the movement of the body. The anterior prolongations are placed across the spine, and belong to that part of the pelvis known by the name of the 
iliac bone; those of the back part are placed longitudinally, and parallel to the median crest of the os sacrum, belonging to the ischial bone of the pelvis, and rising towards the place to which are joined the lateral prolongations of the last sacral vertebra. The two posterior alæ are distant from each other, but the anterior ones unite in the centre of the animal, and, with the high crest of the first three vertebræ of the os sacrum, form a cross below the centre of the posterior and heaviest part of the shell. The iliac bone descending from this spot inclines a little inferiorly, forming at its lower end the artieulation for the thigh termed the acetabulum, into which enters the hemispherical head of the femur. The direction of that part of the principal posterior ramus of the pelvis, termed the ischium, runs almost horizontally towards the place of the posterior ascending ala, which is a subcylindrical and very thick bone, extending inferiorly into a long perpendicular and slightly inclined plate. The os pubis, on the contrary, is very slender, similar to a small rod, which extends a little at the lower end, unites with the ischium, and forms a symphysis pubis, which until now was not known in the Glyptodon, as it is absent in all the pelves discovered. For this reason, we must ealculate that it was very slender and delicate, being perhaps a little open in the centre, and merely united by cartilaginous substance, which is also the case with the Peludos and with the Matacos of the present day.

We perceive behind the pelvis the vertebral column of the tail, which is rather strong and composed of loose vertebræ of different number in different species. Each vertebra possesses a thick cylindrical part below, and a vertebral arch above, from which issue three perpendicular prolongations anteriorly and one horizontal one, with two obtuse points posteriorly. Of these the central one is the spinous process, and the other four the oblique processes. There issues from each side of the body of the vertebra, and between these processes, a transverse process with an elevation at its extremity. All these parts gradually diminish in a posterior direction, the last vertebra being a conical body without any arch or process on its surface. Generally the three vertebræ at the base of the tail are not only the largest, but also differ by their more extended transverse processes; in the following ones this process is shorter, and at the end more reclinate, because it is these vertebræ which are connected with the caudal rings, and the three basal ones are not.

I am only able to state with exactitude the number of the caudal vertebræ of G. spinicaudus; they are ten, of which six are met with in the caudal rings. According to the specimens exhibited in the Museum, we can calculate with exactitude that 
$G$. clavipes had at least thirteen or fifteen and $G$. tuberculatus seventeen or eighteen of these vertebræ.

The ribs of the Glyptodon are very slender, and broader than thick. Each one has a rather long head, with an articular surface on the two sides, adapted to the two articulations, which are almost united, like a $\boldsymbol{x}$, in the excavations of the external side of the lateral processes of the spinal canal. Immediately behind the head they are delicate, then gradually expand and assume a cylindrical form. They unite with the sternum by the medium of strong sternocostal bones, of which there are five pairs, and some loose ones; but, as the sternum is wanting, I cannot exactly describe this part of the skeleton. Probably it was very delicate, and has been broken in consequence. Neither have I seen, up to this day, the clavicle of this animal, which it ought to have, as is demonstrated by the analogy of the existing Armadillos.

The general number of ribs of the G. spinicaudus is fourteen pairs, of which three pairs unite with the first, trivertebral bone of the vertebral canal, and eleven pairs with the second bone.

The form of the scapula is very peculiar, as it is a very slender and long plate of a rhomboidal form, rather short and round in the anterior portion, but very long and acute posteriorly. There arises from the external surface, a little before the centrum, a crest, low at the commencement, which descends down to the articular cavity for the arm, to which it prolongs itself in a very strong, flattened, and curved process, like a pothook, which is the acromion. Behind this is found the rather narrow articulatory cavity for the arm, a little concave and elongate, and with a short protuberance on the fore part of its inner side, which is termed the coracoid process.

The bones of the arm and of the leg are very robust, especially those of the latter. The humerus has the form of a mashorca, a little curved inferiorly, and the two bones of the forearm are united in such a manner that the pronation and supination of the hand is impossible; the hand appears to have possessed little power of rotation. The carpus comprises seven small bones, but wants the os unciforme of the hand of Man. The form of the os pisiforme is very peculiar, as it is a long and broad bone, of the form of a small tongue, united articularly with the ulna. The largest bones of the interior of the hand are the metacarpals, with the exception of the thumb, which is small, and is prolonged downwards into a small round head. The thumb is destitute of phalanges, excepting one small ungual phalanx, which is connected with the metacarpal. The other three toes have two very short phalanges on each, and a very large ungual bone.

MM. D'Alton and Huxley have described the hand of Glyptodon as possessing five digits, the first taking the fourth toe for the 
fifth, and the second placing the thumb in the place of the fifth toe, calculating that the animal most resembled Dasypus, which has five toes on the hand, and not Praopus, which possesses only four. But the construction of the armour, especially of its horny covering, demonstrates that the Glyptodon was more similar in its construction to Praopus than to Dasypus.

The leg is very strong: undoubtedly the femur is the strongest of all the bones of the skeleton. At its head there is no cavity for the ligamentum teres, and from the outer side of the head arises a very prominent trochanter major. We also see a corresponding prolongation on the outer side of the external inferior condyle.

The tibia and the fibula are united into one bone largely perforated in the middle ; and the foot is very thick, high, and short, with a calcaneum rather prominent posteriorly, which proves that the animal was plantigrade, like the Armadillos. The bones of the tarsus are complete; but those of the fore part are very short, like the metacarpals of the five toes. These have the general configuration of those in unguieulated animals, as the ungual bones are very broad and strong.

We shall finally conclude this description with the notice of the fact that in the hand as well as in the foot there are peculiar bones, which are the sesamoid bones. There are three similar bones in the hand for the three toes next the thumb, which are developed below the phalanges beyond the ungual bone. But in the foot there are ten sesamoid bones, one in each toe, excepting the "hallux," and below the second anterior ungual phalanx, and two on the inferior part of the metatarsal bones of the three median digits. These last have a very peculiar form, as they are divaricated, to permit the principal digital tendons to pass through them. There is another bone of a very peculiar form in the centre of the hand, to which the tendons of the toes are attached. A similar bone also exists in some existing Armadillos, and is described by Cuvier in his work 'Recherches sur les Ossemens Fossiles,' tom. v. p. 128, tab. 2. figs 12 \& 13.

\section{X.-On the Menispermacea. \\ Вy John Miers, F.R.S., F.L.S. \&c.}

[Continued from p. 53.]

\section{Odontocarya.}

THis is the only South-American form, as Calycocarpum is the sole North-American genus, of the Heterocliniece hitherto known, all the other eleven genera of this tribe belonging to Asia or Africa. The plant on which this genus was established was found by me in the Organ Mountains as far back as 1828, and Ann. \& Mag. N. Hist. Ser. 3. Vol. xiv. 


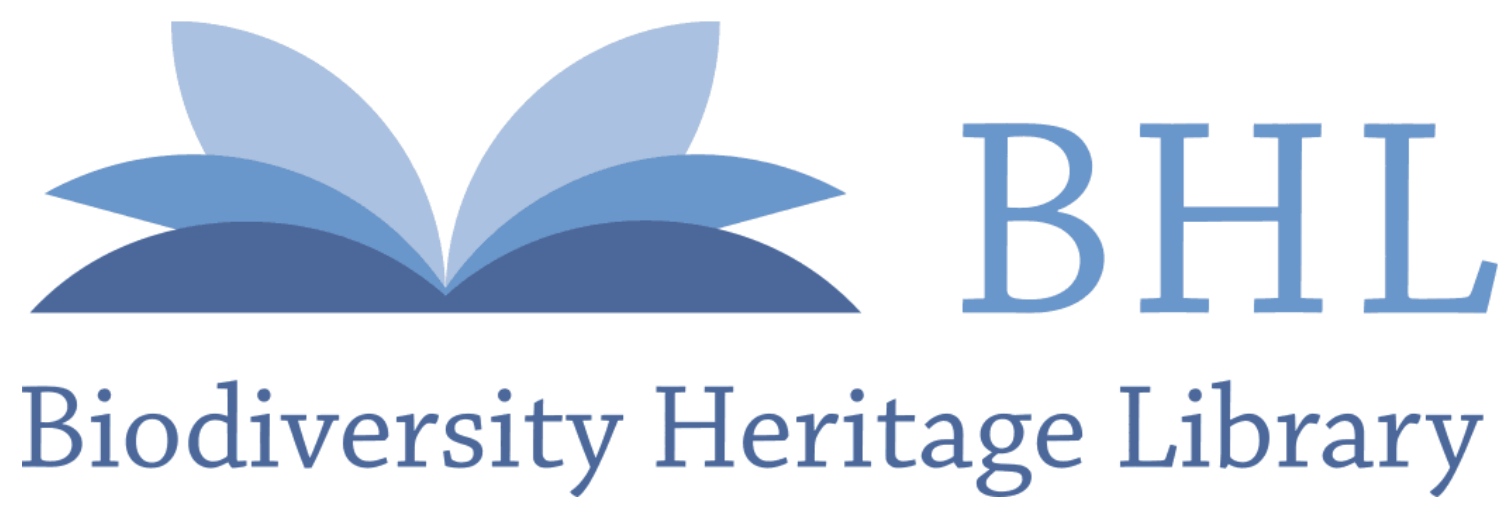

Burmeister, Hermann. 1864. "IX.-Observations on the various species of Glyptodon in the Public Museum of Buenos Ayres." The Annals and magazine of natural history; zoology, botany, and geology 14, 81-97.

View This Item Online: https://www.biodiversitylibrary.org/item/72305

Permalink: https://www.biodiversitylibrary.org/partpdf/61462

\section{Holding Institution}

University of Toronto - Gerstein Science Information Centre

\section{Sponsored by}

University of Toronto

\section{Copyright \& Reuse}

Copyright Status: NOT_IN_COPYRIGHT

This document was created from content at the Biodiversity Heritage Library, the world's largest open access digital library for biodiversity literature and archives. Visit BHL at https://www.biodiversitylibrary.org. 